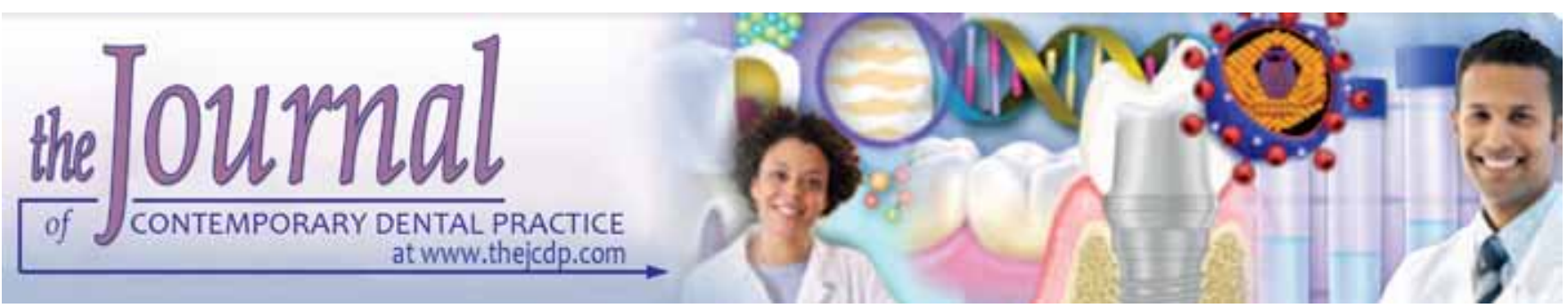

\title{
Oral Paleomicrobiology: Study of Ancient Oral Microbiome
}

\author{
${ }^{1}$ Namrata Dagli, ${ }^{2}$ Rushabh Dagli, ${ }^{3}$ Kusai Baroudi, ${ }^{4}$ Bassel Tarakji
}

\begin{abstract}
Background: Paleomicrobiology is a special branch of micropaleontology concerned with the study of bacterial fossils. We have used the term 'oral paleomicrobiology', as in this review we have focused on the ancient oral microflora. Recently, dental calculus and dental pulp have been identified as rich sources of ancient microbial DNA. Study of this ancient genetic material opens a new door to the ancient world. This review gives an overview of history of ancient DNA research, various techniques of analyzing ancient DNA in dental calculus and dental pulp, and the implications of the oral paleomicrobiology.
\end{abstract}

Materials and methods: A comprehensive literature search was performed in the following databases-pubmed, medline and google scholar for studies published before 10 April, 2015. The following keywords were used-'ancient DNA', 'ancient oral flora, 'oral paleomicrobiology' and 'oral microbiome', '16S rRNA sequencing'. To obtain additional data, a manual search was performed using the reference lists of selected articles.

Result: As a result of literature search, 27 articles were found in pubmed, 12 in google scholar and one in medline. Eight more articles were selected from the reference list of selected articles.

Conclusion: The combination of microbiology and paleontology has brought a revolution in the study of human evolution and microbial communities. The naturally well-preserved samples of microbial DNA from dental pulp and microbial colonies trapped in dental calculus are a potential source of microbial genetic material, which will prove invaluable in resolving mysteries of

${ }^{1}$ Former Member of Ethics Committee, Care Institute of Medical Science, Ahmedabad, Gujarat, India

${ }^{2}$ Vyas Dental College and Hospital, Jodhpur, Rajasthan, India

${ }^{3}$ Department of Restorative Dental Sciences, Alfarabi Colleges Riyadh, Saudi Arabia

${ }^{4}$ Department of Oral and Maxillofacial Sciences, Alfarabi Colleges, Riyadh, Saudi Arabia

Corresponding Author: Namrata Dagli, Former Member of Ethics Committee, Care Institute of Medical Science Ahmedabad, Gujarat, India, Phone: 8141703838, e-mailr.j.dagli@gmail.com the past. This may be a beginning of a new era of oral paleomicrobiology, which will contribute in our studies about prevention of disease by establishing symbiosis between human beings and their microbiome.

Keywords: Ancient microbiome, Oral microbiome, Oral paleomicrobiology

How to cite this article: Dagli N, Dagli R, Baroudi K, Tarakji B. Oral Paleomicrobiology: Study of Ancient Oral Microbiome. J Contemp Dent Pract 2015;16(7):588-594.

Source of support: Nil

Conflict of interest: None

\section{INTRODUCTION}

Paleomicrobiology is a special branch of micropaleontology concerned with the study of microfossils. The term 'microfossils' refers to the fossils of bacteria. ${ }^{1}$ As the name suggests, this branch is related to the study of ancient human microflora, but the scope of this branch is much broader as it includes studies of human evolution, human migration and evolution of bacteria.

We have used the word oral paleomicrobiology for the first time in this review, as we are focusing on the oral microflora. Oral paleomicrobiology, here refers to the study of ancient oral flora, their interactions within their colonies and with the host; with the use of advanced bimolecular techniques, like polymerase chain reaction (PCR) and 16S rRNA phylotyping.

The oral ecosystem is full of diversity and harbors second most diverse human microbiome after gut. As described by Warinner et al, the oral cavity is an entire world unto itself, populated by fusobacteria, streptococci and treponemes. ${ }^{2}$ Researches have shown that despite the fact that oral cavity is subjected to so many changes, e.g. temperature and $\mathrm{pH}$ due to different types of food intake, are in direct contact with the external environment; oral microbiome maintains site-specificity within individuals and among individuals. It is also found to be related with the gut microbiome. Thus, study of ancient oral 
microbiome gives us important clues of life of ancient world. By comparing the present normal flora with that of ancient time, we can understand the effect of change in diet and lifestyle on the microbiome; and also it will help in understanding the adaption of microorganisms to survive in oral cavity and development of drug resistance.

All these informations will give us important clues in maintaining the health and promote microorganisms to contribute in health rather than causing disease.

Recent literature is full of studies on microbiome in health and disease. This review gives an overview of major historical events in ancient DNA research, different methods of analysis of ancient DNA in dental calculus and dental pulp samples obtained from ancient oral cavity, and the implications of the oral paleomicrobiology.

\section{MATERIALS AND METHODS}

A comprehensive systematic review was conducted in the following databases-PubMed, medline and google scholar for studies published before 10 April, 2015. The following keywords were used-'ancient DNA', 'ancient oral flora', 'oral paleomicrobiology', 'oral microbiome' and '16s rRNA sequencing'. To obtain additional data, a manual search was performed using the reference lists of included articles.

Inclusion criteria: Studies only related to dental calculus, dental pulp and dentine were selected.

Articles were initially screened by reading the 'title' and thereafter the 'abstracts'. Duplicate articles were removed and studies not satisfying the inclusion criteria were excluded. The remaining articles were screened in the final stage by reading the full-text and those not meeting inclusion criteria were excluded.

\section{RESULTS}

As a result of literature search, 27 articles were found in PubMed, 12 articles in google scholar and one in medline. Eight more articles were selected from the reference list of selected articles. Duplicate articles were removed. The total number of articles included in the present review is 42 .

\section{HISTORY}

The era of paleomicrobiology was started only few decades back, when first ancient DNA was extracted from a dried muscle of an extinct zebra-like species (Equus quagga). ${ }^{3}$ Soon after this discovery, first human DNA was detected in a muscle-extract from a predynastic Egyptian mummy. ${ }^{4}$ The next important event was successful DNA sequencing of Neanderthal-type specimen by Krings et $\mathrm{al}^{5}$ Mitochondrial genomes of mammoths were also extracted. ${ }^{6}$
The next important events were recovery of first genome sequence of a 4,000 years old palaeo-eskimo from a bunch of hair from museum sample and a draft sequence of the Neanderthal genome., ${ }^{7,8}$ A DNA from molar tooth excavated at the Denisova cave was used to reconstruct full mitochondrial sequence.

The use of dental calculus in archeological studies has been started only few decades back. The first biomolecular analysis of dental calculus was done in 1996 and aimed to identify Streptococcus mutans. ${ }^{9}$ In 2011, the preservation of bacterial DNA within dental calculus was confirmed by gold-labeled antibody transmission electron microscopy. ${ }^{10}$ Adler et al used 16S rRNA gene amplicons to demonstrate that dental calculus preserves an oral microbiome profile. ${ }^{11}$

\section{Reservoirs of Oral Microbiome-Dental Pulp and Dental Calculus}

The oral microbiome is the second largest humanassociated microbial community, after the gut. Dental pulp and dental calculus have been identified as potential reservoirs for the oral microbiome. ${ }^{12}$ However, there are some studies, which have mentioned about the archeological use of other dental tissues, such as dentin, enamel and cementum. However, all these were not as popular as dental calculus.

\section{Dental Pulp}

The DNA of infectious agents in dental pulp has been identified as an archeologically important specimen to study various infective diseases in the past. ${ }^{13}$

It is well-known that dental pulp is a highly vascular tissue. The density of vessels in the dental pulp is comparable to that of the human brain. ${ }^{14}$ Therefore, whenever body gets infected, the chances are very high that causative microorganisms will be found in the pulp. In an experimental study done on the Guinea pigs, presence of colonizing bacteria in pulp was detected when infected with the non-commensal strictly intracellular bacterium. ${ }^{15}$ The DNA remnants from systemic pathogens causing bacteremia had previously been shown to be present in the ancient dental pulp. ${ }^{16,17}$

The genetic material can be detected in dead bacteria even years after cell death. ${ }^{18}$ Bartonella quintana was detected in dental pulp from the 4000 years old human sample by Drancourt et al in $2005 .^{13}$

The main reasons which make dental pulp suitable for study of retrospective diagnosis of infectious disease are:

- It is surrounded by dentin and enamel, and hence naturally protected from environmental contamination. 
- Vascularity is as high as compared to the brain. Therefore, there are high chances that bacteria causing systemic infection can be found in pulp. ${ }^{14}$

- Durability in archeological samples. ${ }^{16}$ It is naturally sterile. Only in conditions like bacteremia, the ancient dental pulp contains the genetic material of the causative bacteria in amounts adequate for investigation. ${ }^{16}$

Although the use of dental pulp is supported by some studies, there are studies which show that dental pulp is contaminated by the microorganisms entered through apical foramen. ${ }^{12,15}$

\section{Dentin}

Dentin is not commonly used in archeological studies for obtaining ancient DNA, may be due to very less amount of DNA obtained from it. But, recent studies have shown that there is a strong binding affinity between DNA and dentin. In a study done by Malin Brundin et al when DNA extracted from Fusobacterium nucleatum was incubated with dentin, the dentin-bound DNA was found to be recoverable by PCR after 3 months; whereas in controls (i.e. without dentin), DNA was not detectable even after 4 weeks. ${ }^{19}$ This is due to the abundance of hydroxyapatite in dentin, which has a strong stabilizing effect on DNA and protects its degradation caused by environmental factors. ${ }^{20}$

\section{Dental Calculus}

Dental calculus has been identified as a potential substrate for the study of genomic analysis of ancient oral microflora and their host. ${ }^{21-23}$ During the 1980s, dental calculus was documented in a range of archeological populations, and systematic protocols were developed for recording dental calculus distribution and severity. ${ }^{24-28}$ In dental calculus, which shows appositional growth pattern, several microorganisms of the oral cavity are trapped. Thus, it is a rich source of the genetic material of oral microflora.

Several published literatures are evidence of its use in archeological studies. The following features make it archeologically important:

- Dental calculus is a very common finding of the oral cavity. In dental calculus obtained from samples that are thousands of years old, microbes of past humanassociated microbiota remained preserved. ${ }^{11}$

- Contamination does not change its content. Ancient calculi were clearly more similar to those from modern dental calculus, plaque, and saliva samples than environmental samples. This shows that DNA obtained from calculus was not contaminated. ${ }^{11}$
A study done by Warinner et al shows no evidence of altered mineralization in ancient dental calculus; whereas tissue degradation, loss of organic matter, and altered mineralization patterns in dentine and cementum, as a result of environmental contamination, was observed. ${ }^{12}$

- Rich source of microbial genetic material. The amount of DNA obtained from dental calculus is very high as compared to other sources. According to Warinner et al, DNA obtained from dental calculus was $437 \mathrm{ng} / \mathrm{mg}$, whereas from the dentin of same tooth the amount obtained was $0.6 \mathrm{ng} / \mathrm{mg}^{12}$

Dental calculus is one of the richest sources of microbial DNA in the oral cavity. Several studies have mentioned its use in the study of ancient human diet too. Therefore, the calculus being so much important archeologically, should be handled carefully. Optimal sampling guidelines for dental calculus are lacking, either in terms of sample quantity or sampling location. ${ }^{12}$ Following are some suggestions for the guidelines of sample collection of calculus:

- Supragingival and subgingival calculi should be collected and analyzed separately as they differ in terms of composition and etiology. However, it is difficult to differentiate the two in absence of soft tissue, as the archeological subgingival calculus is not always darkened as in living patients.

- Collecting calculus samples from multiple teeth is recommended in order to obtain representative data of individual, which can be compared with other individuals.

- The dentition should be photographed, and the details about location and amount of calculus should be documented properly before sample collection. ${ }^{29}$

- Sampling of surrounding dentin and/or bone helps to identify contamination burden of the burial environment. As dentin and bone are sterile during life, their analysis can be useful in identifying bacterial contamination. ${ }^{12}$

- Reasonable quantity of sample material should be preserved for future research. ${ }^{12}$

\section{Cultivation of Uncultivable Microorganism- Modern Techniques of DNA Analysis}

The newer methods enable us to cultivate the bacteria which were considered uncultivable till now due to our dependence on culture-dependent techniques of microbiological analysis. It is estimated that only $1 \%$ of the microbial community is cultivable when conventional culture media are used. With the advancement in molecular biology and development of techniques like 16 rRNA 
sequencing, it is now possible to identify and study the microorganisms previously unknown due to limitations of conventional methods.

The main problem in the study of DNA of the archeological specimen was scarcity of the sample. However, now it is possible to amplify the DNA sample with PCR technique.

\section{An Introduction to PCR}

Polymerase chain reaction is an in vitro method of nucleic acid synthesis by which a particular segment of DNA can be specifically replicated, a technique so sensitive that even a single molecule of DNA can be amplified.

The technique of DNA amplification requires two oligonucleotide primers that flank the sample DNA fragment, which is to be amplified. Following steps are involved:

- Repeated cycles of heat denaturation of DNA.

- Annealing of primers to their complementary sequences.

- Extension of annealed primers with DNA polymerasethese primers hybridize to the opposite strands of the target sequence and are oriented in such a way that the process of DNA synthesis by polymerase occurs between the primers.

Since the extension products are capable of binding primers, they also participate in the reaction. As a result, double amount of target DNA is produced in each and every cycle. Accumulation of the specific target fragment can be represented by $2^{n}$, where $n$ is the number of cycles of amplification.

The main advantage of this technique is that it does not require a high amount of sample. A specimen with an average molecular length of few 100 base pairs is usually sufficient, but it is necessary that the specimen contains at least one intact DNA strand within the region to be amplified.

The limitation of this technique:

- Only a few cells usually up to $10^{4}$ can be used, otherwise accumulation of cellular debris starts inhibiting the reaction. $^{30}$

- Contamination from human DNA even in small amount can affect the result as it can be presented as double sequences at the polymorphic position. It can be avoided by precaution in handling various solutions and use of multiple extracts of same individuals from different tissues. ${ }^{31}$

\section{S rRNA Phylotyping}

In 1960s, it was observed by Dubnau et al that $16 \mathrm{~S}$ rRNA gene sequence relationships were quite stable with time in Bacillus spp. ${ }^{32}$ The relative stability as compared to other genes was attributed to the importance of the $16 \mathrm{~S} r \mathrm{RNA}$ as a critical component of cell function. This finding formed the basis of genomic identification of various microbial species. The comparison of $16 \mathrm{~S}$ rRNA gene sequences can be used in classifying bacterial strains at species and subspecies level.

The 16S rRNA gene sequence is about $1,550 \mathrm{bp}$ long and is composed of both variable and conserved regions. The $16 \mathrm{~S}$ rRNA gene was chosen for the species identification and study of evolution because:

- $16 \mathrm{~S}$ rRNA gene is ubiquitous in bacteria, and so relationships can be measured among all bacteria.

- This gene sequence is already identified for large no. of strains. Over 90,000 16S rRNA gene sequences are deposited in GenBank, the largest databank of nucleotide sequences. Therefore, we have sufficient data against which new unknown sequences can be compared. ${ }^{33}$

- The gene is large enough to provide comparable and statistically valid data.

Universal primers are used either at the beginning of the gene at the $540 \mathrm{bp}$ region or at the end of the sequence at about the $1,550 \mathrm{bp}$ region. The sequence in between these two ends is variable, and hence used for the comparative taxonomy. ${ }^{34}$ Although 500 and $1500 \mathrm{bp}$ are commonly used, sequences in databases can be of various lengths. $^{33}$

Limitation: Provides only a phylogenetic description and does not provide any information about gene functionality.

\section{Shotgun Metagenomics}

Rather than amplifying and sequencing a single gene or target region, shotgun metagenomics amplifies randomly, and gives an advantage of sequencing a subset of the total DNA in a sample. ${ }^{12}$ Besides phylogenetic description, it provides information regarding interaction of microbes within the community, genome structure, gene function, population genetics and microheterogeneity, and lateral gene transfer among members of an uncultured community. Novel genes and proteins like DNA polymerase and antibiotic-resistance determinants have been discovered. ${ }^{35}$

The general strategy for a metagenomic study is:

- Directly extraction of DNA from a clinical sample.

- Construction of a library of inserts those are multiplexed and sequenced in order to articulate the full genetic potential of a sample.

- Unassembled signature genes, such as 16S rRNA can be classified by searching against databases (such as green genes or RDP-II).

- Sequencing of a heterogenous mixture of DNA. ${ }^{36}$ 


\section{Advantages}

- Most informative genetic approach to microbiome characterization.

- It generates whole genome sequencing data, therefore, not only allows analysis of taxonomy or phylogeny, but also provides information regarding gene content and functional potential of genome.

- Recovering extinct microbial genomes for which no reference genomes exist.

Limitation: Most difficult to analyze and interpret.

\section{Implications of Oral Paleomicrobiology}

The human oral cavity has been compared with a kingdom by Antonie van Leeuwenhoek. According to Warriner etal, 'it is an entire world unto itself'. Even within the oral cavity, the microorganisms show site specificity. Tongue, oral mucosa, surface of teeth and dental calculus-they all form different habitats with different microorganisms. It is an ecosystem which is so diverse that it should be studied under a separate branch. Here, we are describing the scope of oral paleomicrobiology:

- Human evolutionary history: Recently, human mitochondrial DNA has been linked to human evolution. Some unique properties, like maternal inheritance, lack of recombination, high mutation rate, etc. have made it the molecule of choice for studying history of human evolution. ${ }^{37}$

- Study of human migration: The use of oral microbiome has been proposed as an alternative to Helicobacter pylori for investigation of human migration. The studies done by Henne et al demonstrated presence of geographically specific protein-coding bacterial genes from human saliva [such as the glucosyltransferases (GTF) gene from Streptococcus oralis], which could be helpful in resolving past events of migration of human population. ${ }^{38}$

- Evolution of microorganisms: Evolution of human is very closely linked with microorganisms. Evolution of microorganisms would help us understand the pathogenesis of various diseases. The DNA of microorganisms obtained from fossils remained preserved for centuries and has been helpful in analysis of diseases, like tuberculosis, leprosy and plague. With increasing antibiotic resistance, there is possibility of recurrence of outbreaks of infectious diseases. ${ }^{39,40}$ All these informations would be helpful in prevention of many diseases. We can also get information regarding process of adaptation of microorganisms to survive in oral cavity and development of drug resistance within them. For example, specific genetic adaptations of a Bifidobacterium taxon which maintains a balanced gastrointestinal (GIT) microflora (Bifidobacterium dentium Bd1), to a lifestyle as a cariogenic microorganism in the oral cavity. ${ }^{41}$

- Bacterial taxa found on host body are site specific and their frequency fluctuates between the time points. Because of subject-specificity and relative stability of salivary microbiota, its use in forensic medicine for person identification as an alternative or complementary approach has been suggested by Lazarevic et al. ${ }^{42}$

- Study of retrograde diagnosis of infectious disease: whenever human body is infected, the causative agent is also found in pulp ${ }^{43}$. Enclosed by dental hard tissues, dental pulp is naturally protected from environmental contamination, and hence DNA of pathogens in dental pulp has been identified as an archeologically important specimen to study various infective diseases in the past. ${ }^{14,15,44}$

\section{LIMITATION OF STUDY}

This article may be subjected to publication bias as only published studies have been included. Only the manuscripts written in English language have been included.

\section{CONCLUSION}

The discovery of ancient DNA in the oral cavity, and biomolecular advancement facilitating its study, has opened new doors to ancient world. The combination of microbiology and paleontology has brought a revolution in the study of human evolution and microbial communities. The naturally well-preserved samples of microbial DNA from dental pulp and microbial colonies trapped in dental calculus are a potential source of microbial genetic material which will prove invaluable in resolving mysteries of the past. The features, like interand intra-individual site-specificity of oral microbiome make this very important part of archeological studies. Its increasing popularity among archeologists may start beginning of a new era of oral paleomicrobiology which will contribute in our studies about prevention of disease by establishing symbiosis between a human beings and their microbiome. Further studies related to ancient microbial DNA may provide information regarding the effect of the shift in diet, use of antibiotics and use of oral hygiene products on oral microbiome.

\section{REFERENCES}

1. Bhawsar S. Fossil bacteria: Paleomicrobiology and detection of fossil age. Available at: http://www.biotecharticles.com/ Biology-Article/ Paleomicrobiology-and-Detection-of-FossilAge-650.html. 
2. Warinner C, Speller C, Collins MJ. A new era in palaeomicrobiology: prospects for ancient dental calculus as a long-term record of the human oral microbiome. Philos Trans R Soc Lond B Biol Sci 2015;370(1660):20130376.

3. Higuchi R, Bowman B, Freiberger M, Ryder OA, Wilson AC. DNA sequences from the quagga, an extinct member of the horse family. Nature 1984;312:282-284.

4. Pääbo S. Molecular cloning of ancient Egyptian mummy DNA. Nature 1985;314:644-645.

5. Krings M, Stone A, Schmitz RW, Krainitzki H, Stoneking M, Pääbo S. Neandertal DNA sequences and the origin of modern humans. Cell 1997;90(1):19-30.

6. Rogaev EI, Moliaka YK, Malyarchuk BA, Kondrashov FA, Derenko MV, Chumakov I, Grigorenko AP. Complete mitochondrial genome and phylogeny of pleistocene mammoth Mammuthus primigenius. PLoS Biol 2006;4(3):e73.

7. Rasmussen M, Li Y, Lindgreen S, Pedersen JS, Albrechtsen A, Moltke I, Metspalu M, Metspalu E, Kivisild T, Gupta R, et al. Ancient human genome sequence of an extinct Palaeo-Eskimo. Nature 2010;463(7282):757-762.

8. Green RE, Krause J, Briggs AW, Maricic T, Stenzel U, Kircher M, Patterson N, Li H, Zhai W, Fritz MH, et al. A draft sequence of the Neandertal genome. Science 2010 7;328(5979):710-722.

9. Linossier A, Gajardo M, Olavarria J. Paleomicrobiological study in dental calculus: Streptococcus mutans. Scanning Microsc 1996;10(4):1005-1013.

10. Preus HR, Marvik OJ, Selvig KA, Bennike P. Ancient bacterial DNA (aDNA) in dental calculus from archaeological human remains. J Archaeol Sci 2011;38(8):1827-1831.

11. Adler CJ, Dobney K, Weyrich LS, Kaidonis J, Walker AW, Haak W, Bradshaw CJ, Townsend G, Soltysiak A, Alt KW, et al. Sequencing ancient calcified dental plaque shows changes in oral microbiota with dietary shifts of the Neolithic and industrial revolutions. Nat Genet 2013;45:450-455.

12. Warinner C, Rodrigues JF, Vyas R, Trachsel C, Shved N, Grossmann J, Radini A, Hancock Y, Tito RY, Fiddyment S, et al. Pathogens and host immunity in the ancient human oral cavity. Nat Genet 2014;46(4):336-344.

13. Drancourt M, Tran-Hung L, Courtin J, Lumley Hd, Raoult D. Bartonella quintana in a 4000-year-old human tooth. J Infect Dis 2005;191(4):607-611.

14. Kim S. Regulation of pulpal blood flow. J Dent Res 1985;64: 590-596.

15. O'Connell KP, Skowronski EW. Emerging and Endemic Pathogens: advances in Surveillance, Detection and Identification (NATO Science for Peace and Security Series A: Chemistry and Biology). Gerard Aboudharam, Michel Drancourt, Didier Raoult. Applications of Paleomicrobiology to the Understanding of Emerging and Re-emerging Infectious Diseases. Springer 2010;91(8).

16. Holden C. Old dental pulp points to plague. Science 1998;282: 619.

17. Papagrigorakis, Manolis J, Yapijakis C, Synodinos, Philippos N. Paleomicrobiology: past human infections. Berlin: Springer; 2008. Chapter 10, Typhoid fever epidemic in ancient Athens.

18. Brundin M. Stability of bacterial DNA in relation to microbial detection in teeth. 2013. p. 35. Available at: http:/ / umu.divaportal.org/smash/get/diva2:662554/INSIDE01.pdf
19. Brundin M, Figdor D, Johansson A, Sjögren. Preservation of bacterial DNA by human dentin. J Endod 2014;40(2):241-245.

20. Brundin M, Figdor D, Johansson A, Sjögren U. Elsevier DNA binding to hydroxyapatite: A potential mechanism for preservation of microbial DNA. J Endod 2014;39(2):211-216.

21. De La Fuente C, Flores S, Moraga M. DNA From human ancient bacteria: a novel source of genetic evidence from archaeological dental calculus. Archaeometry 2013;55(4): 767-778.

22. Hardy K, Blakeney T, Copeland L, Kirkham J, Wrangham R, Collins M. Starch granules, dental calculus and new perspectives on ancient diet. J Archaeol Sci 2009;36(2):248-255.

23. Henry AG, Brooks AS, Piperno DR. Microfossils in calculus demonstrate consumption of plants and cooked foods in Neanderthal diets (Shanidar III, Iraq; Spy I and II, Belgium). Proc Natl Acad Sci USA 2011;108(2):486-491.

24. Dobney K, Brothwell D. Dental calculus: Its relevance to ancient diet and oral ecology. Teeth Anthropol BAR Int Ser 1986;291:55-81.

25. Allison, Marvin J. Paleopathology at the Origins of Agriculture. Orlando, FL: Academic Press; 1984. Paleopathology in Peruvian and Chilean populations; p. 515-529.

26. Cassidy, Claire M. Paleopathology at the Origins of Agriculture. Orlando, FL: Academic Press; 1984. Skeletal evidence for prehistoric subsistence adaptation in the central Ohio river valley; p. 307-345.

27. Kennedy, Kenneth A. Paleopathology at the origins of agriculture. Orlando, FL: Academic Press; 1984. Growth, nutrition and pathology in changing paleodemographic settings in South Asia; p. 169-192.

28. Dobney K, Brothwell D. A method for evaluating the amount of dental calculus on teeth from archaeological sites. J Archaeol Sci 1987;14(4):343-351.

29. Buikstra, Jane E; Ubelaker, Douglas H. Standards for data collection from human skeletal remains. Arkansas Archeological Survey Research Series. Fayetteville, Arkansas, Wahington: Arkansas Archeological Survey; 1994. p. 206.

30. Innis, Michael A, Gelfand, David H, Sninsky, John J. et al. PCR Protocols: A Guide to Methods and Application. California: Academic press; 1990. Amplification of genomic DNA; p.13-20.

31. Pääbo S. Ancient DNA: extraction, characterization, molecular cloning, and enzymatic amplification. Proc Natl Acad Sci USA 1989;86(6):1939-1943.

32. Dubnau D, Smith I, Morell P, Marmur J. Gene conservation in Bacillus species. I. Conserved genetic and nucleic acid base sequence homologies. Proc Natl Acad Sci USA 1965;54(2): 491-498.

33. Clarridge JE III. Impact of $16 \mathrm{~S}$ rRNA gene sequence analysis for identification of bacteria on clinical microbiology and infectious diseases. Clin Microbiol Rev 2004;17(4):840-862.

34. Chen $K$, Neimark H, Rumore P, Steinman CR. Broad range DNA probes for detecting and amplifying eubacterial nucleic acids. FEMS Microbiol Lett 1989;48(1):19-24.

35. Handelsman J. Metagenomics: Application of genomics to uncultured microorganisms. Microbiol Mol Biol Rev 2004; 68(4):669-685.

36. Grice EA, Segre JA. The human microbiome: Our second genome. Annu Rev Genomics Hum Genet 2012;13:151-170.

37. Pakendorf B, Stoneking M. Mitochondrial DNA and human evolution. Annu Rev of Genomics Hum Genet 2005;6:165-183. 
38. Henne K, Li Jing, Stoneking M, Kessler O, Schilling $\mathrm{H}$, Sonanini A, Conrads G, Horz HP. Global analysis of saliva as a source of bacterial genes for insights into human population structure and migration studies. BMC Evol Biol 2014;14:190.

39. Harkins KM, Buikstra JE, Campbell T, Bos KI, Johnson ED, Krause J, Stone AC. Screening ancient tuberculosis with qPCR: challenges and opportunities. Philos Trans R Soc Lond B Biol Sci 2015;370(1660):20130622.

40. Bos KI, Jäger G, Schuenemann VJ, Vågene ÅJ, Spyrou MA, Herbig A, Nieselt K, Krause J. Parallel detection of ancient pathogens via array-based DNA capture. Philos Trans R Soc Lond B Biol Sci 2015;370(1660):20130375.

41. Ventura M, Turroni F, Zomer A, Foroni E, Giubellini V, Bottacini F, Canchaya C, Claesson MJ, He F, Mantzourani M, et al. The Bifidobacterium dentium Bd1 genome sequence reflects its genetic adaptation to the human oral cavity. PLoS Genet 2009;5(12):e1000785.

42. Lazarevic V, Whiteson K, Hernandez D, François P, Schrenzel J. Study of inter- and intra-individual variations in the salivary microbiota. BMC Genomics 2010;11:523.

43. Jhajharia K, Parolia A, Shetty KV, Mehta LK. Biofilm in endodontics: a review. J Int Soc Prevent Communit Dent 2015;5:1-12.

44. La VD, Aboudharam G, Raoult D, Drancourt M. Paleomicrobiology. Berlin Heidelberg: Springer-Verlag; 2008. Dental pulp as a tool for the retrospective diagnosis of infectious. p. 175-196. 